\title{
The effect of protection on fish populations in the Ses Negres Marine Reserve (NW Mediterranean, Spain)
}

\author{
MARC RIUS \\ Departament de Biologia Animal, Facultat de Biologia, Universitat de Barcelona. Avda. Diagonal 645, 08028, Barcelona, \\ Spain. E-mail: marcriusvil@ub.edu
}

\begin{abstract}
SUMMARY: This work is the result of a 3-year monitoring programme for assessing the effect that the Ses Negres marine reserve has had on fish populations. Species richness (based on fish species that are considered to be reserve effect indicators), and the size structure of 4 species vulnerable to angling and spear fishing were studied by visual censuses conducted both inside and outside the marine reserve. Analysis of fish populations inside the reserve showed a reserve effect (larger sizes, higher abundance and richer fish assemblages) when compared to the non-reserve sites, especially by the end of the study period. The results highlight the importance of marine reserves for the recovery of fish populations. Future management plans are discussed for this marine reserve.
\end{abstract}

Keywords: Ses Negres, MPA, rocky fish, NW Mediterranean, reserve effect.

RESUMEN: El EFECTO DE LA PROTECCIÓN EN LAS POBLACIONES DE PECES DE LA RESERVA MARINA DE SES NEGRES (MEDiterRÁNEO NOROCCIDENTAL, EsPAÑA). - Este trabajo es el resultado de un programa de seguimiento de 3 años estudiando el efecto que la reserva marina de Ses Negres ha tenido sobre las poblaciones de peces. La riqueza específica (basada en especies de peces consideradas indicadoras del efecto reserva), y la estructura de tallas de 4 especies vulnerables a la pesca con caña y arpón fueron estudiadas utilizando censos visuales llevados a cabo dentro y fuera de la reserva marina. El análisis de las poblaciones de peces dentro de la reserva mostró un efecto de reserva (tamaños más grandes, mayor abundancia y riqueza específica) cuando se compararon con estaciones fuera de la reserva, sobre todo al final del periodo de estudio. Los resultados destacan la importancia de las reservas marinas para la recuperación de las poblaciones de peces y se discuten futuros planes de gestión para esta reserva marina.

Palabras clave: Ses Negres, MPA, peces costeros, Mediterráneo NO, efecto reserva.

\section{INTRODUCTION}

Establishing marine reserves, also called Marine Protected Areas (MPAs), has been extensively proven to be an important tool for recovering previously over-fished populations (Castilla, 2000; Harmelin, 2000; Hyrenbach et al., 2000), especially fish assemblages (Buxton, 1993; Polunin and Roberts, 1993; Wantiez et al., 1997; Russ and Alcala, 1998).

The NW Mediterranean coast has been exploited by humans since ancient times (de Lumley, 1975), and today in some regions fish populations show signs of over-exploitation (Lleonart, 1996). Along this coast, spear fishing and angling are the main activities affecting rocky benthic fish populations, especially large fish carnivores (Harmelin et al., 1995). Prohibiting fishing by establishing MPAs along this coast has allowed the abundance and average size of fish populations to increase (the so called reserve effect) within these areas (GarcíaRubies and Zabala, 1990; Francour, 1994; Harmelin et al., 1995; Claudet et al., 2006). In addition, rare fish species which are especially vulnerable to spear 
fishing have recently been found in MPAs (Harmelin, 2000). Other more common species, such as labrid, serranid and sparid species, which are extremely vulnerable to angling as a result of their curious nature (Harmelin et al., 1995), can only be found in large size classes in the MPA (GarcíaRubies and Zabala, 1990). As most rocky fish species along the Mediterranean coast are protogynous or protandrous hermaphrodites (Francour, 1994), the selective overfishing of the largest gender can affect species viability.

Recently, a number of MPAs have been created along the NE coast of Spain (Badalamenti et al., 2000), some of which are located in high intensity tourist areas where professional and recreational fishing is a widespread activity. One of these MPAs is the Ses Negres MPA located on the "Costa Brava" and established in 1993. From interviews with local fishermen it is known that this coastline in recent years has been dramatically affected by recreational fishing, especially during the summer months (Soley, 2000). Establishing the Ses Negres MPA meant prohibiting all forms of professional and recreational fishing activities, anchoring and SCUBA diving.

This study is the first long term study undertaken in the Ses Negres MPA and it aims to evaluate the effects of protection on fish populations in terms of their diversity, abundance and size structure.

\section{MATERIALS AND METHODS}

The Ses Negres MPA $\left(41^{\circ} 58^{\prime} \mathrm{N}, 03^{\circ} 13^{\prime} \mathrm{E}\right)$ is comprised of $1.3 \mathrm{~km}$ of NE orientated rocky coastline and protects 80 ha of marine territory. This area runs from the shore to a depth of 40 meters and is composed of both sandy and rocky bottoms.

The non-destructive visual census technique has been the most widely used to assess fish abundance and richness in situ (Harmelin-Vivien et al., 1985; Kimmel, 1985; Harmelin, 1987; Francour, 1994; Lipej et al., 2003). The specific methodology applied in this study was based on visual censuses following the transect method used by GarcíaRubies and Zabala (1990). Thus, fish richness and size structure data were collected along permanent transects of $50 \times 5 \mathrm{~m}$ using SCUBA.

A preliminary study assessing the abundance and diversity of the fish assemblage was done in randomly selected months from the summer of 1994 to the end of 1996. Surveys were done at several sites both inside and outside the MPA, hereafter R and NR respectively. The adjacent stretch of coastline 1 $\mathrm{km}$ south from the southern limit of the reserve was used as the non-protected location. All surveys were done on the rocky bottoms because in coastal areas this is where fishing pressure is greatest (Francour, 1994), and where, if a reserve effect exists, it can be reliably reported (Harmelin et al., 1995). All sites had similar substrata topographic complexity (rocky substrata with scattered boulders), benthic community and a gentle NE slope. In general, the fish assemblage was very similar to the one described by García-Rubies and Zabala (1990) on a nearby coast.

For the current study 2 sites for each location ( $R$ and NR) were randomly selected from the group of sites identified during the preliminary study. As fish distribution is depth dependant (Bell, 1983; Lipej et al., 2003), two depths (deep - 10 to $15 \mathrm{~m}$, and shallow - 5 to $8 \mathrm{~m}$ depth) were used per site. Starting on the northern side, all transects were conducted perpendicularly to the NE rocky slope at each site. Iron bars glued to the rocky bottom indicated the initial and final points of each transect.

As seasonality, weather conditions, fish behaviour and reproduction influence fish species richness and abundance throughout the year (Harmelin et al., 1995; Soley, 2000; Lipej et al., 2003), all surveys were done on randomly selected sunny days between June and September each year. The number of surveys (i.e. sampling days) done per year was 9 (1997), 9 (1998) and 7 (1999). For each sampling day, all selected transects from the different sites and depths were surveyed once.

Fish species that could be indicative of the reserve effect were identified based on previous studies in the same region (García-Rubies and Zabala, 1990; Harmelin et al., 1995; Soley, 2000). Following the categories of the target fish species defined by Harmelin et al. (1995), "type A" was used to assess fish species richness, and the species selected for the shallow transects were Dentex dentex, Diplodus cervinus, Diplodus puntazzo, Sparus aurata, Spondyliosoma cantharus and Pagellus erythrinus, while for the deep transects the species selected were Conger conger, Dentex dentex, Dicentrarchus labrax, Diplodus cervinus, Diplodus puntazzo, Epinephelus marginatus, Labrus merula, Labrus viridis, Muraena helena, Phycis phycis, Sciaena umbra, Sparus aurata, Spondyliosoma cantharus and Scorpaena scrofa. Inside this target 
species type, Harmelin et al. (1995) included 2 sparid species Diplodus sargus and Diplodus vulgaris, which are very valuable catch to both professional and recreational fishermen (Francour, 1994; Harmelin, 2000). Data from the preliminary study showed that these 2 species were recorded in all surveys. As a result, they would not have been good indicators of the reserve effect in terms of species richness. However, they were useful for comparing size structures of populations inside and outside the reserve. Thus, the maximum length of the fish was measured using a $40 \mathrm{~cm}$ scale glued onto a $1 \mathrm{~m}$ stick. The scale was brought as close as possible to the fish in order to achieve the best estimate of its length. The same was done for the "type B" species Serranus cabrilla and Coris julis (Harmelin et al., 1995). Four size classes were established (small, medium, large and very large) in $10 \mathrm{~cm}$ intervals from 0 to $40 \mathrm{~cm}$ for the Diplodus species, and in 5 $\mathrm{cm}$ intervals from 0 to $20 \mathrm{~cm}$ for $C$. julis and $S$. cabrilla.

a)
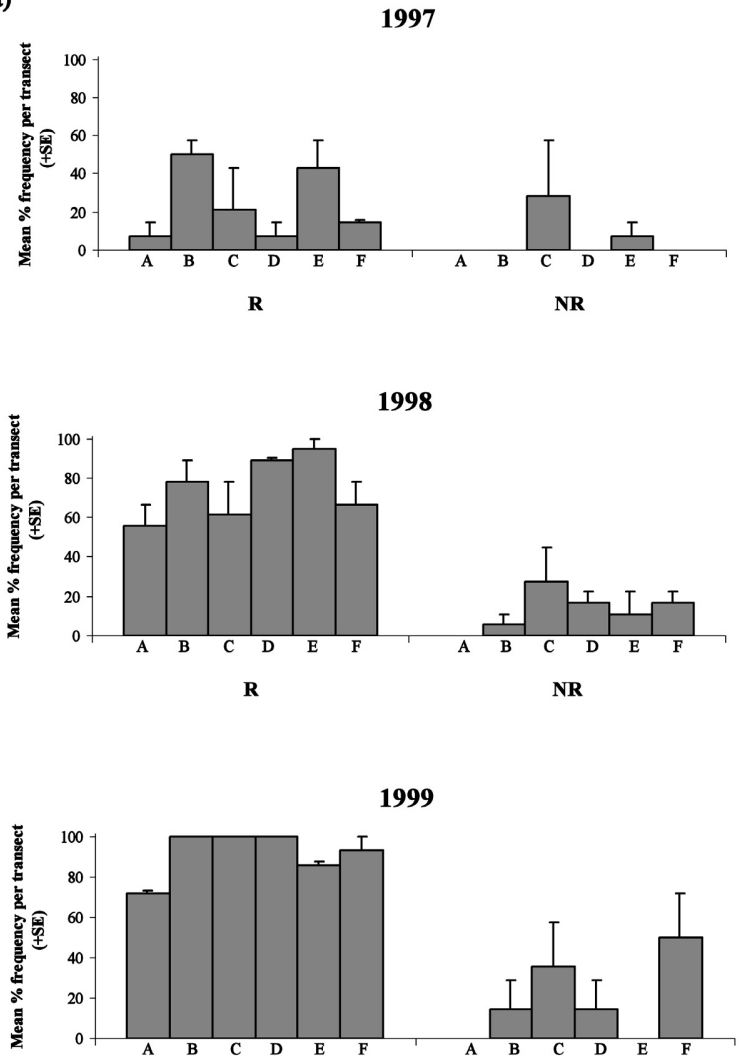

FIG. 1. - Fish species richness. Mean $\%$ frequency of each species occurrence per transect in each location and year in: a) shallow and b) deep

The transects were conducted by 2 divers swimming slowly, taking approximately 15 minutes to cover each transect. The first diver assessed fish species richness by recording the presence of the selected fish species, while the second diver measured the 4 target species in the transect. As it was impossible to measure all target species at one time, two species were measured in each transect. Consequently, population size structures of $D$. sargus and D. vulgaris were obtained from the shallow transects, while the population size structures of $C$. julis and S. cabrilla were obtained from the deep transects. This bathymetrical segregation was defined based on what García-Rubies and Zabala (1990) found along a nearby coast. For C. julis, females and males in the preliminary phase could be recognized easily as they have different colour patterns from the terminal phase males, and are smaller (Harmelin et al., 1995).

The effects of protection and year on species richness and size structure data were analyzed using

b)
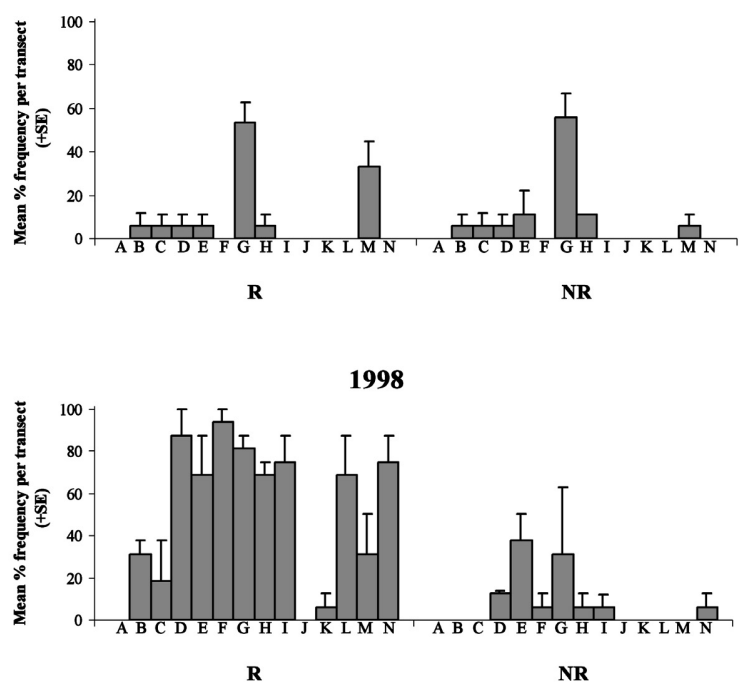

1999

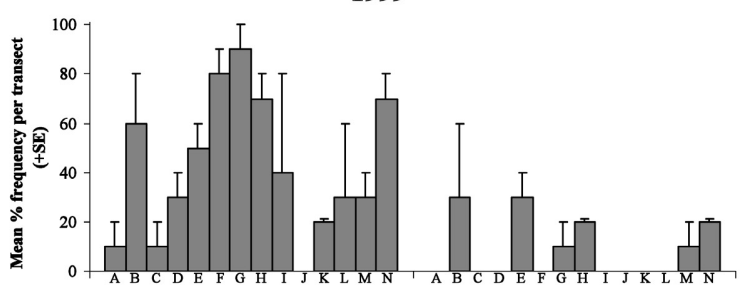
transects. Letters under the $\mathrm{X}$ axis indicate the fish species selected, for the shallow transects $(\mathrm{A}=$ Dentex dentex, $\mathrm{B}=$ Diplodus cervinus, $\mathrm{C}$ $=$ Diplodus puntazzo, $\mathrm{D}=$ Sparus aurata, $\mathrm{E}=$ Spondyliosoma cantharus, $\mathrm{F}=$ Pagellus erythrinus $)$ and the deep transects $(\mathrm{A}=$ Conger conger, $\mathrm{B}=$ Dentex dentex, $\mathrm{C}=$ Dicentrarchus labrax, $\mathrm{D}=$ Diplodus cervinus, $\mathrm{E}=$ Diplodus puntazzo, $\mathrm{F}=$ Epinephelus marginatus, $\mathrm{G}=$ Labrus merula, $\mathrm{H}=$ Labrus viridis, $\mathrm{I}=$ Muraena helena, $\mathrm{J}=$ Phycis phycis, $\mathrm{K}=$ Sciaena umbra, $\mathrm{L}=$ Sparus aurata, $\mathrm{M}=$ Spondyliosoma cantharus, $\mathrm{N}=$ Scorpaena scrofa). 
a 2-way ANOVA test, in which protection and year were fixed factors. All analyses were performed using SYSTAT software (v. 11, SPSS Inc., 2004).

\section{RESULTS}

In the shallow transects, 6 species were found in $\mathrm{R}$ throughout all 3 years, while in NR only 2 species were found in 1997, 5 in 1998 and 4 in 1999 (Fig. 1a). The mean $\%$ frequency of species per transect in $\mathrm{R}$ increased gradually during the 3 years, while in $\mathrm{NR}$, the frequency remained low. The ANOVA test showed significant effects of protection $\left(\mathrm{F}_{1,90}=\right.$ 28.087, $\mathrm{p}<0.001)$ and year $\left(\mathrm{F}_{2,90}=6.352, \mathrm{p}=0.003\right)$, while the effect of the interaction was, by a very small margin, not significant $\left(\mathrm{F}_{2,90}=3.057, \mathrm{p}=\right.$ 0.052). In the deep transects undertaken in R, 7 of the 14 target species were found in 1997,12 species in 1998 and 13 in 1999, while in NR, 7 species appeared in 1997, 7 in 1998 and 6 in 1999 (Fig. 1b). Again, there was an increase in mean $\%$ frequency of species per transect in R, but not in NR. The effects of the factors and their interaction were significant (2-way ANOVA: protection, $\mathrm{F}_{1,186}=23.624$, $\mathrm{p}<0.001$; year, $\mathrm{F}_{2,186}=9.664, \mathrm{p}<0.001$; interaction, $\left.\mathrm{F}_{2,186}=5.982, \mathrm{p}=0.003\right)$.

In general, for both $D$. sargus and D. vulgaris, larger individuals were found in R than in NR, especially from 1998 onwards (Figs. 2a,b). In R, all size classes increased during the study period. The very large size class $(31-40 \mathrm{~cm}$ ) appeared in R for both species in 1998 and 1999, and in the last year of the study there was an increase in the abundance of this size class. Both species showed unimodal distributions, with medium and large sizes being the most abundant size classes, especially noticeable for $D$. sargus. The size structures of $D$. vulgaris were more varied, dominated, however, by small and medium size classes. The ANOVA tests showed strong effects of protection, year and interaction on both species (all situations $\mathrm{p}<0.001$, except interaction for D. vulgaris, $\mathrm{F}_{2,2576}=3.904, \mathrm{p}=0.02$ ).

The size structure of both $C$. julis and S. cabrilla (Figs. 2c,d) showed the same pattern as that of the sparid species. For $C$. julis, the female and primary males were the most abundant types $(<15 \mathrm{~cm})$, while all larger individuals were terminal phase males and were only encountered in R (Fig. 2c). Significant effects of the factors and their interaction were found (2-way ANOVA: protection, $\mathrm{F}_{1,363}=35.578$; year, $\mathrm{F}_{2,363}=16.466$; interaction, $\mathrm{F}_{2,363}=15.029$; all situations $\mathrm{p}<0.001)$. In 1997 the middle size class of S. cabrilla was the most abundant at all sites, but in the following 2 years the importance of this size class was reduced, and both the larger and smaller size classes increased, especially in R (Fig. 2d). Again, significant effects of all factors and the interaction were found (2-way ANOVA: protection, $\mathrm{F}_{1,1028}=106.281, \mathrm{p}<0.001$; year, $\mathrm{F}_{2,1028}=30.193$, $\mathrm{p}<0.001$; interaction, $\mathrm{F}_{2,1028}=5.263, \mathrm{p}=0.005$ ).

\section{DISCUSSION}

This study suggests the presence of a reserve effect on fish populations in the Ses Negres MPA both in terms of species richness and the population structure of the target species. In all cases, protection and year were critical factors, with the highest species richness and the largest individuals being found almost exclusively in the MPA, especially by the end of the study period.

In terms of fish species richness, all the studied species were found in $\mathrm{R}$ except one, Phycis phycis (Fig. 1). Other rare species such as Dicentrarchus labrax, Sparus aurata, Epinephelus marginatus or Sciaena umbra were only found in the MPA, as has been reported in other NW Mediterranean marine reserves (García-Rubies and Zabala, 1990; Francour, 1994; Harmelin et al., 1995).

The so called reserve effect is mainly defined by the refuge effect (larger fish and higher species richness) (Russ and Alcala, 1998), but also indicates cascade effects which result from an increase in the number of predators within the MPA that thereby reduces the number of prey (Moreno et al., 1986; Francour, 1994; Castilla, 1999; Pinnegar et al., 2000). Consequently, the increase in the number and size of predators inside the Ses Negres MPA might have altered the trophic cascades by increasing the pressure on prey.

Fishing pressure on reproductively mature adults distorts populations towards juveniles, which can modify social conditions within populations (Harmelin et al., 1995) and obstruct reproduction in hermaphrodite species (Buxton, 1993; Francour, 1994). In this study, the size structures of the 4 target species studied highlight the effect of protected areas as refuges of large spawners.

Mediterranean MPAs have become more popular in recent years as a result of the increase in tourism 


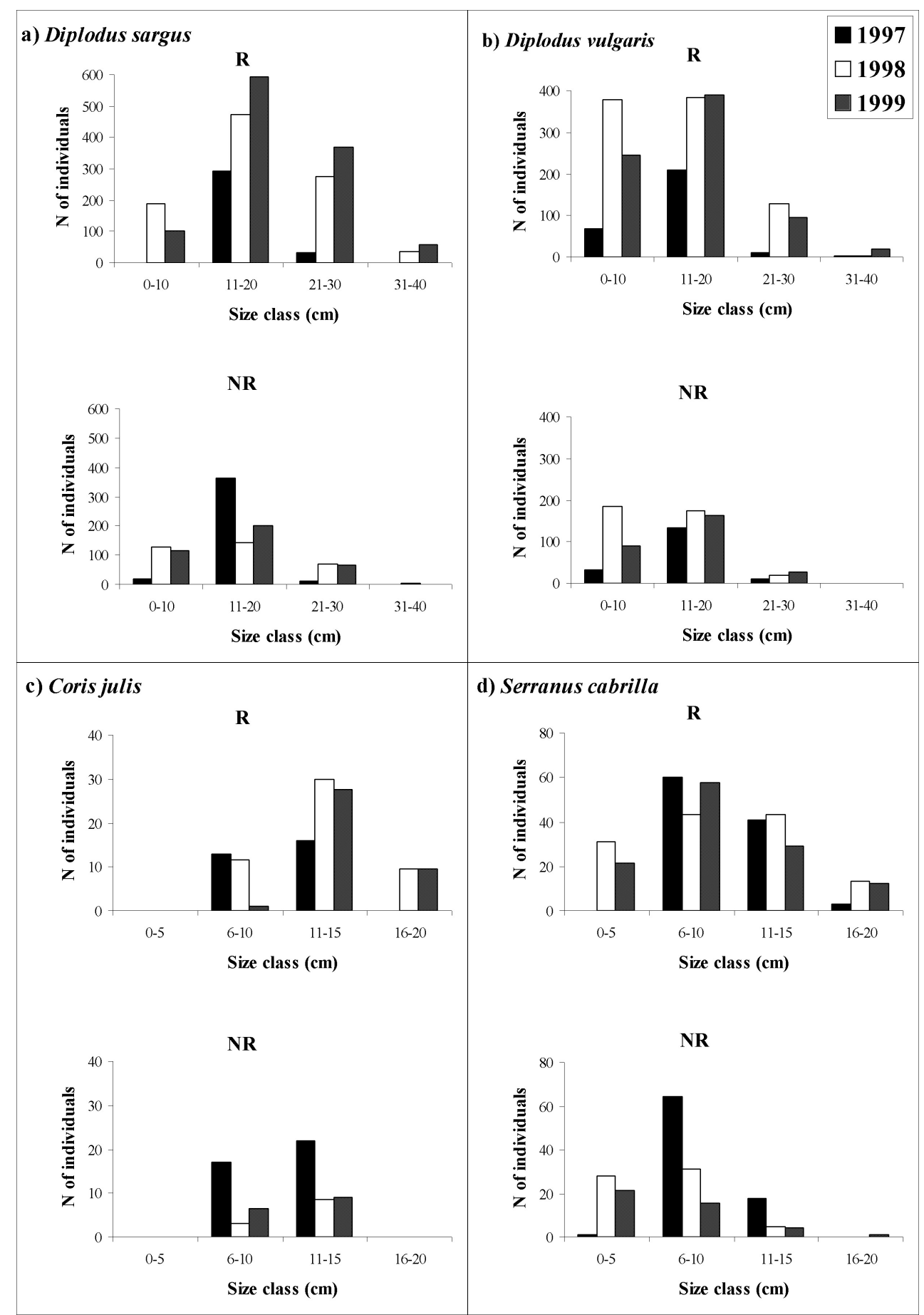

FIG. 2. - Size structure of the target species: a) Diplodus sargus, b) Diplodus vulgaris, c) Coris julis and d) Serranus cabrilla. The total number $(\mathrm{N})$ of individuals was obtained by pooling all transects from each year and location.

(Harmelin, 2000). This has produced an increase in recreational activities in MPAs that, in some cases, have negatively affected marine communities such as sessile organisms (Garrabou et al., 1998; Coma et al., 2004), altered fish behaviour (Harmelin et al., 1995) or simply impeded the recovery of fish populations (Lipej et al., 2003). The fact that in Ses
Negres MPA all forms of human activity are prohibited has prevented these problems from occurring and if any illegal activity took place during the study period, it did not negate the reserve effect on fish populations.

In some Mediterranean MPAs controlled activities have been permitted as these do not interfere 
with the main objective of recovering overfished populations in MPAs (Harmelin, 2000). Two examples of the controlled activities include the increase in economic benefits by means of well controlled tourism (Francour, 1994), and maintaining regional fishing through small-scale artisanal fishing that has proven not to interfere with the recovery of fish populations (Harmelin, 2000). In the Ses Negres MPA, a multiple-use management plan could be considered only if an integrative approach involving local fishermen, conservation measures, social agents and local administration is implemented.

Although no previous data is available regarding fish populations before this marine reserve was created, this study establishes a baseline from which further studies can be done in the Ses Negres MPA. Furthermore, future studies based on the standard methodology used for this study can be applied to other MPAs, and therefore comparisons can be made with the Ses Negres MPA.

\section{ACKNOWLEDGEMENTS}

I thank all the staff from the "Associació Nereo", especially G. Mas, F. Soley and M. Ventura, for assistance in the field and for contributions to the earlier drafts of this manuscript. Special thanks to J. Murray for proof reading the manuscript. I am grateful to S. de Juan for her helpful comments. The surveys were supported by funds from the Catalan Government.

\section{REFERENCES}

Badalamenti F., A.A. Ramos, E. Voultsiadou, J.L. Sánchez-Lizaso, G. D’Anna, C. Pipitone, J. Mas, J.A. Ruiz Fernandez, D. Whitmarsh and S. Riggio. - 2000. Cultural and socio-economic impacts of Mediterranean marine protected areas. Environ. Cons., 27: 110-120.

Bell, J.D. - 1983. Effects of depth and marine reserve fishing restrictions on the structure of a rocky reef fish assemblage in the North-Western Mediterranean Sea. J. Appl. Ecol., 20: 357-369.

Buxton, C.D. - 1993. Life-history changes in exploited reef fishes on the east coast of South Africa. Environ. Biol. Fish., 36: 47-63.

Castilla, J.C. - 1999. Coastal marine communities: trends and perspectives from human exclusion experiments. Trends Ecol. Evol., 14: 280-283.

Castilla, J.C. - 2000. Roles of experimental marine ecology in coastal management and conservation. J. Exp. Mar. Biol. Ecol., 250: 3-21.

Claudet, J., D. Pelletier, J.-Y. Jouvenel, F. Bachet and R. Galzin. -
2006. Assessing the effects of marine protected area (MPA) on a reef fish assemblage in a northwestern Mediterranean marine reserve: Identifying community-based indicators. Biol. Conserv., 130: 349-369.

Coma, R., E. Pola, M. Ribes and M. Zabala. - 2004. Long-term assessment of temperate octocoral mortality patterns, protected vs. unprotected areas. Ecol. Appl., 14: 1466-1478.

de Lumley, H. - 1975. Cultural evolution in France in its paleoecological setting during the Middle Pleistocene. In: G.L. Isaac and K.W. Butzer (eds.), After the Australopithecines: stratigraphy, ecology and culture in the Middle Pleistocene, pp. 745-808. Mounton, The Hague.

Francour, P. - 1994. Pluriannual analysis of the reserve effect on ichthyofauna in the Scandola natural reserve (Corsica, northwestern Mediterranean). Oceanol. Acta, 17: 309-317.

García-Rubies, A. and M. Zabala. - 1990. Effects of total fishing prohibition on the rocky fish assemblages of Medes Islands Marine Reserve (NW Mediterranean). Sci. Mar., 54: 317-328.

Garrabou, J., E. Sala, A. Arcas and M. Zabala. - 1998. The impact of diving on rocky sublittoral communities: a case study of a bryozoan population. Conserv. Biol., 12: 302-312.

Harmelin, J.G. - 1987. Structure et variabilité de l'ichtyofaune d'une zone rocheuse protegeé en Mediterranée (Parc National de Port-Cros, France). P.S.Z.N.I.: Mar. Ecol., 8: 263-284.

Harmelin, J.G. - 2000. Mediterranean marine protected areas: some prominent traits and promising trends. Environ. Conserv., 27: 104-105.

Harmelin, J.G., F. Bachet and F. García. - 1995. Mediterranean marine reserves: fish indices as tests of protection efficiency. P.S.Z.N.I.: Mar. Ecol., 16: 233-250.

Harmelin-Vivien, M.L., J.G. Harmelin, C. Chauvet, C. Duval, R. Galzin, P. Lejeune, G. Barnabe, F. Blanc, R. Chevalier, J. Duclerc and G. Lasserre. - 1985. Evaluation visuelle des peuplements et populations de poissons: méthodes et problèmes. Revue Ecol. - Terre Vie, 40: 467-539.

Hyrenbach, K.D., K.A. Forney and P.K. Dayton. - 2000. Marine protected areas and ocean basin management. Aquatic Conserv., 10: 437-458.

Kimmel, J.J. - 1985. A new species-time method for visual assessment of fishes and its comparison with established methods. Environ. Biol. Fish., 12: 23-32.

Lipej, L., M.O. Bonaca and M. ?i?ko. - 2003. Coastal fish diversity in three marine protected areas and one unprotected area in the Gulf of Trieste (Northern Adriatic). P.S.Z.N.: Mar. Ecol., 24: $259-273$.

Lleonart, J. - 1996. La pesca a Catalunya i la seva gestió. Butll. Inst. Cat. Hist. Nat., 64: 135-158.

Moreno, C.A., K.M. Lunecke and M.I. Lépez. - 1986. The response of an intertidal Concholepas concholepas (Gastropoda) population to protection from man in southern Chile and the effects on benthic sessile assemblages. Oikos, 46: 359-364.

Pinnegar, J.K., N.V.C. Polunin, P. Francour, F. Badalamenti, R. Chemello, M.L. Harmelin-Vivien, B. Hereu, M. Milazzo, M. Zabala, G. D'Anna and C. Pipitone. - 2000. Trophic cascades in benthic marine ecosystems: lessons for fisheries and protected-area management. Environ. Conserv., 27: 179-200.

Polunin, N.V.C. and C.M. Roberts. - 1993. Greater biomass and value of target coral-reef fishes in two small Caribbean marine reserves. Mar. Ecol. Prog. Ser., 100: 167-176.

Russ, G.R. and A.C. Alcala. - 1998. Natural fishing experiments in marine reserves, 1983-1993: community and trophic responses. Coral Reefs, 17: 383-397.

Soley, M. - 2000. Evolució de les poblacions íctiques a la reserva marina de Ses Negres. Unpublished report, Associació Nereo.

Wantiez, L., P. Thollot and M. Kublicki. - 1997. Effects of marine reserves on coral reef fish communities from five islands in New Caledonia. Coral Reefs, 16: 215-224.

Scient. ed.: F. Maynou.

Received Desember 12, 2006. Accepted April 23, 2007.

Published online July 9, 2007. 